\title{
PESTICIDE CONSUMPTION, CENTRAL NERVOUS SYSTEM AND CARDIOVASCULAR CONGENITAL MALFORMATIONS IN THE SOUTH AND SOUTHEAST REGION OF BRAZIL
}

\section{CLEBER CREMONESE ${ }^{1}$, CARMEN FREIRE ${ }^{1}$, ARIANA MACHADO DE CAMARGO ${ }^{2}$, JAIME SILVA DE LIMA ${ }^{3}$, SERGIO KOIFMAN ${ }^{1}$, and ARMANDO MEYER ${ }^{2}$}

\author{
${ }^{1}$ National School of Public Health, Oswaldo Cruz Foundation (FIOCRUZ), Rio de Janeiro, Brazil \\ Environment and Public Health Post-graduation Program \\ ${ }^{2}$ Federal University of Rio de Janeiro (UFRJ), Rio de Janeiro, Brazil \\ Instituto de Estudos em Saúde Coletiva (IESC) \\ ${ }^{3}$ Federal University of Rio de Janeiro (UFRJ), Rio de Janeiro, Brazil \\ Department of Biochemistry
}

\begin{abstract}
Objectives: To investigate the association between per capita pesticide consumption and infant mortality rates from CNS and CVS congenital malformations in microregions in the South and Southeast Region of Brazil. Material and Methods: An ecological study was conducted using data on pesticide expenditure in 1985 and 1996, and deaths caused by CNS and CVS malformations in infants under 1 year old in 1986-1990 and 1997-2001, respectively. Per capita pesticide consumption and infant mortality rates were calculated for each microregion. Microregions were grouped according to quintiles of pesticide consumption, taking the first quintile as reference. The association between pesticide consumption and infant mortality was examined by calculating Spearman correlation coefficients (r) and mortality rate ratios (RR), stratifying by gender and type of microregion (urban or rural). Results: Significant and positive correlations between per capita pesticide consumption and rates of mortality due to CNS and CVS defects were observed in rural but not urban microregions. In general, mortality RRs for the 2 types of malformations in rural microregions were significantly higher in each quintile of pesticide consumption compared to the lowest quintile in the 2 study periods, with elevations ranging between $10 \%$ and 30\%. Likewise, mortality RRs in these microregions showed significant trends of increase across quintiles of pesticide consumption in both study periods. In urban areas, however, mortality RRs from both CNS and CVS malformations were weak and not statistically significant, and a trend of increase of mortality with increasing pesticide usage was not observed. Conclusions: The results show the relevance of pesticide exposure in rural areas with intense agricultural activity, suggesting that such prenatal exposures may be related with the occurrence of certain congenital defects.
\end{abstract}

Key words:

Pesticides, Congenital malformations, Central nervous system, Cardiovascular system, Ecological study

This work was partially supported by the Ministry of Health, the Brazilian National Research Council (CNPq), and the CAPES ("Coordenação de Aperfeiçoamento de Pessoal de Nível Superior"). Cleber Cremonese has a CAPES predoctoral grant, Carmen Freire has a "Jovens Talentos" grant (number A022-2013) from the CNPq (Science Without Borders Program). Jaime Lima and Armando Meyer are supported by the CNPq ("Bolsa de Produtividade em Pesquisa"). Sergio Koifman is supported by the CNPq (grant number 308986/2010-5 and INCT-Cancer Control) and FAPERJ (grant E-26/102.869/2012).

Received: October 17, 2013. Accepted: March 11, 2014.

Corresponding author: C. Freire, Environment and Public Health Post-graduation Program, National School of Public Health, FIOCRUZ, Rua Leopoldo Bulhões, 1480, CEP: 21041-210, Rio de Janeiro, RJ, Brazil (e-mail: cfreire@ugr.es). 


\section{INTRODUCTION}

About $5 \%$ of newborn babies worldwide are affected by birth defects, which contribute significantly to infant mortality rates across different ethnic groups [1-3]. In the USA, birth defects are the main cause of infant mortality, being responsible for $20.1 \%$ of the total number of deaths [4]. In Latin America, congenital anomalies are responsible for $25 \%$ of pediatric hospital admissions and they represent the 3rd cause of mortality among infants in the 1st year of life [5]. In Brazil, after the decrease of deaths from infections-related diseases, infant mortality from congenital defects increased proportionally, going from the 5th to the 2nd most important cause of infant mortality [6]. Nevertheless, prevalence of birth defects is commonly underestimated due to underreporting, which is particularly high in developing countries $[7,8]$. Congenital anomalies of the cardiovascular system (CVS) are the most common type of serious birth defects among live births [9] and are a major cause of postnatal deaths from congenital anomalies. The most common subtypes of CVS malformations include atrial or ventricular septal defects, transposition of the great vessels, persistent truncus arteriosus, teratology of Fallot, and coarctations [10]. Malformations of the central nervous system (CNS) are the 2nd most common type of major congenital anomalies. Most CNS malformations are related to the defects of the neural tube, which usually fuses 18-26 days after ovulation. Failure of closure of the neural tube may lead to anencephaly, encephalocele, spina bifida, or spina bifida occulta. In Brazil, major birth defects represent over $70 \%$ of the total birth defects [8]. Despite the importance of these malformations, the causes of most cases of CVS and CNS malformations are not known. Etiologic factors that have been identified include genetics, maternal illnesses, dietary factors, maternal drug exposures, and maternal and paternal environmental exposures [11-13].

It is well known that the fetus is extremely sensitive to environmental exposures during certain critical windows of development [14]. Animal studies have shown that many pesticides have an impact on production, release, transport, metabolism, and elimination of hormones that regulate homeostasis and other developmental processes [15], raising concern for possible teratogenic effects among exposed human populations. Thus, numerous epidemiological studies have examined the possible association between parental exposures to pesticides and the occurrence of congenital anomalies [3,16-20]. Regarding CNS malformations, parental exposure to pesticides was associated with excess of anomalies such as spina bifida, hydrocephaly, and anencephaly in cohort and casecontrol studies [17,21-23]. Epidemiological evidence of a link between parental exposure to pesticides and CVS is scarcer [24-26].

Developing countries account for $1 / 3$ of global pesticide consumption. In Latin America, Brazil is currently the most important country in pesticide usage and the 3rd largest consumer of pesticides in the world [27]. One previous ecological study in Brazil reported a positive correlation between the state pesticide use in 2000 and deaths from congenital anomalies in 2001 [28]. The present study aimed to explore the association between pesticide consumption and infant mortality caused by CNS and CVS congenital malformations in microregions of the South and Southeast Region of Brazil, using the national information systems.

\section{MATERIAL AND METHODS}

\section{Design and study population}

An ecological study was conducted to examine the association between per capita consumption of pesticides in 1985 and 1996 in microregions of the South and Southeast Region of Brazil (Figure 1) and rates of infant mortality due to CNS and CVS congenital malformations in subsequent periods, i.e. 1986-1990 and 1997-2001. The study population included all deaths among infants under 1 year 


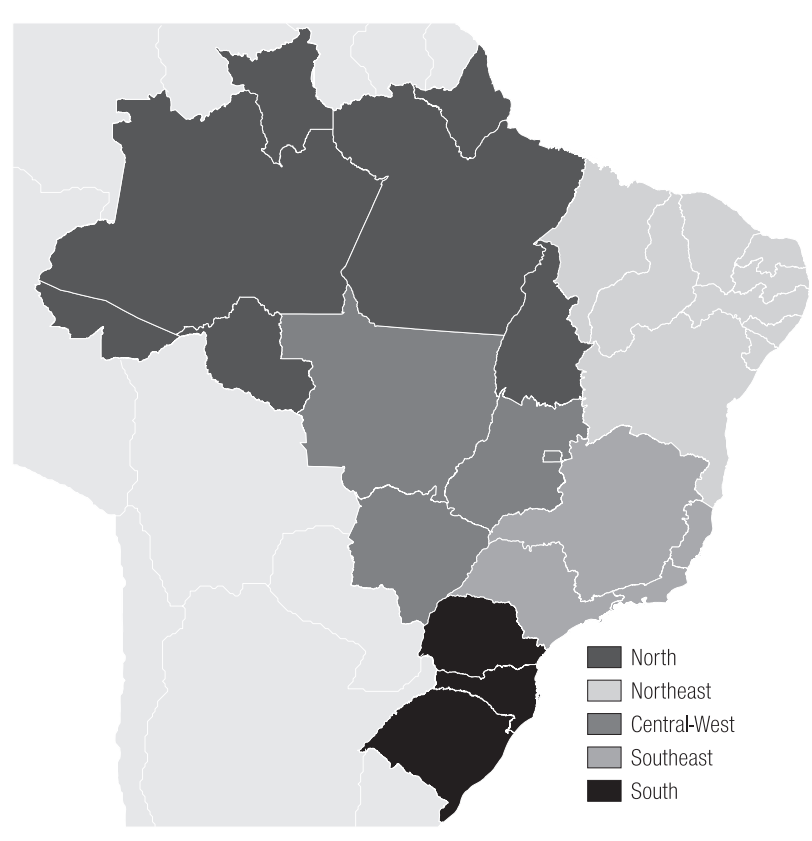

Fig. 1. Regions of Brazil

of age reported in both periods. Considering that Brazil has experienced a steady rise in pesticide use through the last decades, it was hypothesized that women giving birth in 1986-1990 and 1997-2001 were exposed to pesticide levels similar or higher than exposure levels occurring in 1985 and 1996, respectively.

\section{Data collection}

Pesticide consumption

Data on pesticide expenditures in pesticide sales establishments in the study area in the years 1985 and 1996 were collected from the Agricultural Census, which is conducted every 10 years by the Brazilian Institute of Geography and Statistics (IBGE). Per capita consumption of pesticides in 1985 and 1996 was calculated by dividing pesticide expenditures (in cruzeiros, Cr\$, in 1985 and in reais, $\mathrm{R} \$$, in 1996) by the population in each microregion. Data on the population count of each microregion were obtained from the IBGE. The total number of microregions in the study area was 250 (182 rural and 68 urban).

\section{Mortality data}

Information was collected on all deaths from CNS and CVS congenital malformations among infants $<1$ year of age registered in the South and Southeast Region of Brazil. This information was obtained from the Mortality Information System (SIM) of the Health Information Department of the Unified National Health System (DATASUS), Ministry of Health [29]. These morbidities have been included in chapter XVII of the International Classification of Diseases 10 (ICD-10) of the World Health Organization (WHO) as "congenital malformations, deformations and chromosomal abnormalities" since 1996. For the period 1979-1995, CNS and CVS malformations are included in Chapter XIV of ICD-9 as "congenital anomalies".

Thus, data on infant mortality due to CNS malformations (items 740-742 in Chapter XIV of ICD-9 and items Q00-Q07 in Chapter XVII of ICD-10) and CVS malformations (item 747 in Chapter XIV of ICD-9 and items Q20-Q28 in Chapter XVII of ICD-10) were obtained for each microregion according to the study period. Mortality rates for the malformations under study were estimated by dividing the number of deaths due to the referred malformations in infants under the age of 1 year by the total population in this age range per microregion. The population of infants $<1$ year old in the middle of each study period was obtained from the DATASUS [29]. Rates were expressed in terms of deaths per 1000 live births per year.

\section{Statistical analysis}

Spearman correlation analysis was conducted between per capita consumption of pesticides and mortality rates of CNS and CVS malformations in each microregion. Subsequently, the microregions were grouped into quintiles of per capita pesticide consumption. Mortality rate ratios (RR) and their corresponding $95 \%$ confidence intervals $(\mathrm{CI})$ were computed for each quintile, taking the 
first quintile as reference. Linear trend analysis was performed by using the $\mathrm{Chi}^{2}$ test. All analyses were conducted according to the study period, with no stratification, and stratified by gender and according to the microregion type (urban or rural).

For the 1st study period, i.e. 1986-1990, mortality rates according to the ICD-9 were examined in relation to per capita consumption of pesticides in the year 1985, whereas for the 2nd study period, i.e. 1997-2001, the ICD-10 classification and the pesticide consumption data in 1996 were used.

\section{RESULTS}

The average of per capita pesticide expenditure in 1985 was $\mathrm{Cr} \$ 64.33$ (around $\mathrm{R} \$ 0.02$ ) in urban microregions and $\mathrm{Cr} \$ 94.58$ (R\$ 0.03) in rural microregions. Pesticide consumption in 1996 increased up to $\mathrm{R} \$ 11.07$ and $\mathrm{R} \$ 28.56$, respectively (Table 1). In 1985, the mean per capita consumption of pesticides in the lowest quintile was $\mathrm{Cr} \$ 4.10$, while in 2nd, 3rd, 4th and upper quintiles it was $\mathrm{Cr} \$ 15.90$,
Cr\$38.48, Cr\$ 77.59 and Cr\$295.93, respectively. In 1996, the mean value of pesticide consumption in the lowest quintile was $\mathrm{R} \$ 0.77$, and it was $\mathrm{R} \$ 5.05, \mathrm{R} \$ 14.18, \mathrm{R} \$ 29.23$ and $\mathrm{R} \$ 70.02$, respectively, in the following quintiles.

The total number of 29915 deaths caused by CNS and CVS malformations among infants $<1$ year of age was registered in the study periods in microregions in the South and Southeast Region of Brazil. In 1986-1990, 16004 deaths were registered, corresponding to $4 \%$ of the total mortality in that age range. In 1997-2001, the number of registered deaths due to the studied malformations was 13 911, which represented $6.5 \%$ of the total number of deaths. Infant mortality rates per 1000 live births were higher in the 1st study period, and were higher for CVS malformations (Table 2). In general, mortality rates for CNS anomalies were higher in female infants, whereas mortality rates for CVS were higher among male infants (Table 2).

The analysis of the correlation between per capita pesticide consumption and infant mortality due to CNS and CVS malformations is shown in Table 3. The correlations for the totality of microregions were weak and not

Table 1. Pesticide expenditure in microregions in the South and Southeast Region of Brazil, 1985 and 1996

\begin{tabular}{|c|c|c|c|c|c|c|c|c|c|}
\hline \multicolumn{2}{|c|}{ Microregion } & \multirow{2}{*}{$\begin{array}{c}\text { Population } \\
\text { (n) }\end{array}$} & \multicolumn{7}{|c|}{ Per capita pesticide expenditure } \\
\hline year / category & $\mathrm{n}$ & & M & $\min$. & $\mathrm{P} 20$ & $\mathrm{P} 40$ & $\mathrm{P} 60$ & $\mathrm{P} 80$ & $\max$ \\
\hline \multicolumn{10}{|l|}{$1985^{\mathrm{a}}$} \\
\hline urban & 68 & 63188670 & 64.33 & 0.06 & 2.69 & 11.62 & 32.22 & 75.18 & 870.63 \\
\hline rural & 182 & 34354544 & 94.58 & 0.41 & 11.72 & 28.89 & 59.15 & 119.81 & 1031.46 \\
\hline all microregions & 250 & 97543214 & 79.95 & 0.06 & 8.97 & 24.03 & 53.99 & 108.99 & 1031.46 \\
\hline \multicolumn{10}{|l|}{$1996^{\mathrm{b}}$} \\
\hline urban & 68 & 58754381 & 11.07 & 0.01 & 0.27 & 1.78 & 7.83 & 16.73 & 83.13 \\
\hline rural & 182 & 32394353 & 28.56 & 0.18 & 3.76 & 13.11 & 25.01 & 47.32 & 146.28 \\
\hline all microregions & 250 & 91148734 & 19.81 & 0.01 & 2.10 & 9.04 & 20.14 & 40.37 & 146.28 \\
\hline
\end{tabular}

a Pesticide expenditure is given in cruzeiros, $\mathrm{Cr} \$(100 \mathrm{Cr} \$=0.03 \mathrm{R} \$)$.

${ }^{\mathrm{b}}$ Pesticide expenditure is given in reais, $\mathrm{R} \$$.

$\mathrm{M}$ - mean; min. - minimum value; max - maximum value.

P20, P40, P60, P80 - 20th, 40th, 60th and 80th percentiles. 


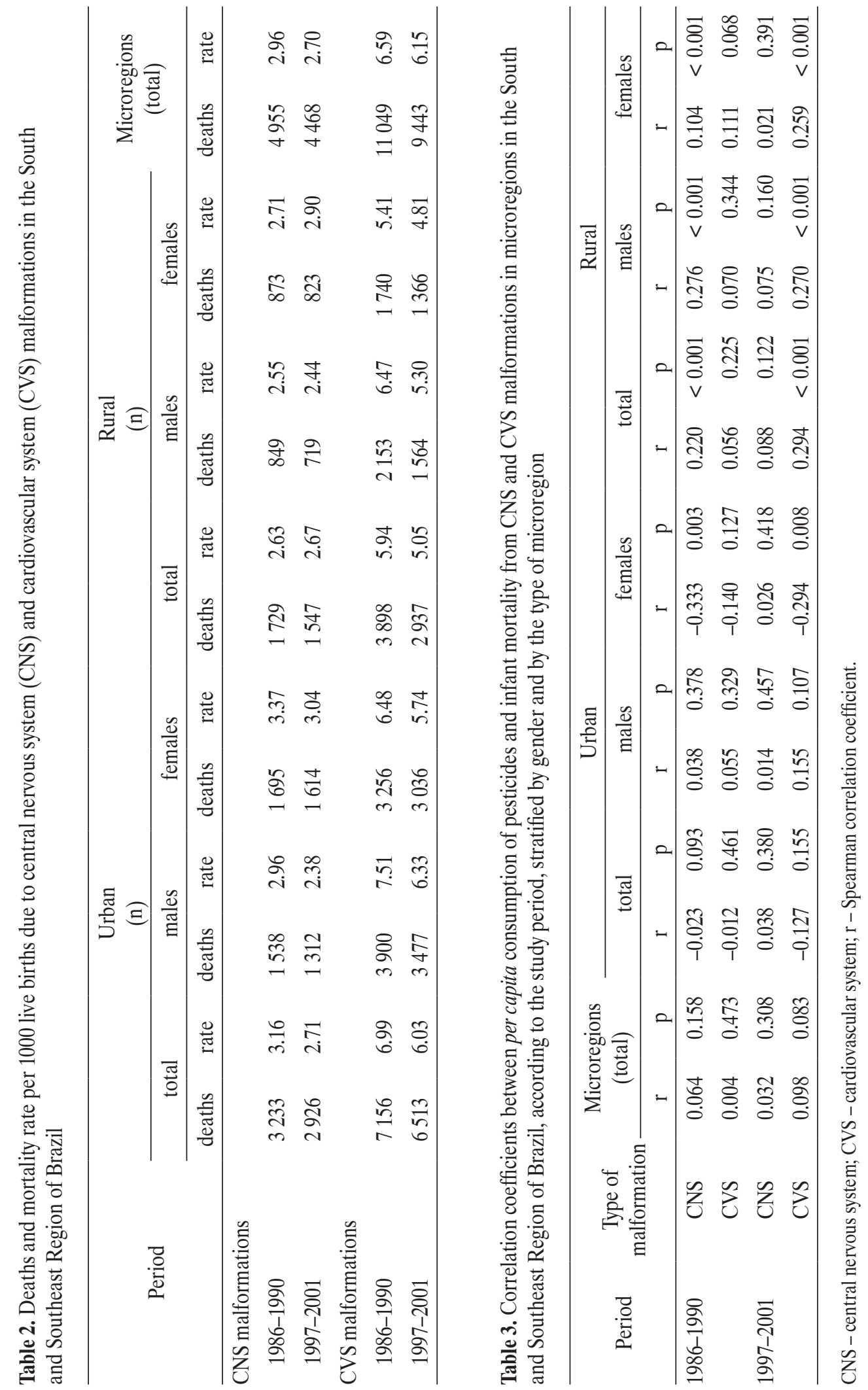


statistically significant in both study periods and for both malformations. In rural microregions, positive and statistically significant correlations $(p<0.001)$ were found for deaths from CNS malformations in the 1st study period (Spearman coefficient, $r=0.22$ ) and for deaths from CVS malformations in the 2nd study period $(\mathrm{r}=0.29)$, both in boys and girls. In contrast, urban microregions showed statistically significant negative correlations between per capita pesticide consumption and female mortality from CNS anomalies in the 1st study period $(\mathrm{r}=-0.33$, $p=0.003$ ) and from CVS malformations in the 2nd study period $(r=-0.29, p=0.008)$.

When all microregions were analyzed together, mortality rate ratios (RR) from CNS and CVS defects in quintiles of per capita consumption of pesticides were, in general, lower than unity and statistically not significant, taking as reference the 1st quintile of consumption (Table 4). However, a significant linear trend of increase of mortality RRs was observed across quintiles of pesticide usage. This increasing trend was seen for both malformations and in the 2 study periods, except for CNS malformations in 1997-2001, which showed slightly elevated RRs (higher than unity), but a non-significant linear trend of increase.
When mortality RRs were calculated separately for urban and rural microregions, results revealed a significant trend of increase of mortality due to CNS and CVS malformations in the rural area according to quintiles of consumption in both study periods (Table 5). In general, RRs in rural microregions were higher than unity and elevations in ratios ranged between $10 \%$ and $30 \%$. These elevations were particularly higher for CNS malformations in 1986-1990 (e.g. RR $=1.29$, 95\% CI: $1.12-1.49$ in the 4th quintile compared to the 1st quintile of pesticide use), and for CVS malformations in 1997-2001 (e.g. RR $=1.22$, 95\% CI: $1.10-1.35$ in the 3rd quintile). In urban microregions, mortality RRs for both CNS and CVS malformations were in general weak and not statistically significant in the 2 study periods, and a trend of increase of mortality with increasing pesticide consumption was not observed.

The trend of increase of RR described for rural microregions in the 1st study period remained statistically significant for male and female mortality due to CNS malformations, and for female mortality caused by CVS malformations (Table 6). In this period, RRs were particularly higher for males and CNS defects ( $\mathrm{RR}=1.34,95 \%$ CI: $1.08-1.66$, in the upper quintile) and for females

Table 4. Infant mortality from CNS and CVS malformations in microregions in the South and Southeast Region of Brazil, according to quintiles of per capita consumption and the study period

\begin{tabular}{lcccccccc}
\hline \multirow{2}{*}{$\begin{array}{c}\text { Pesticide use } \\
\text { quintiles }\end{array}$} & \multicolumn{3}{c}{ CNS } & \multicolumn{3}{c}{ CVS } & \multicolumn{3}{c}{ CNS } & CVS \\
\cline { 2 - 9 } & \multicolumn{1}{c}{$\mathrm{n}$} & $\mathrm{RR}(95 \% \mathrm{CI})$ & $\mathrm{n}$ & $\mathrm{RR}(95 \% \mathrm{CI})$ & $\mathrm{n}$ & $\mathrm{RR}(95 \% \mathrm{CI})$ & $\mathrm{n}$ & $\mathrm{RR}(95 \% \mathrm{CI})$ \\
\hline 1 & 2701 & 1 & 6002 & 1 & 2540 & 1 & 5668 & 1 \\
2 & 685 & $0.82(0.76-0.89)$ & 1485 & $0.80(0.76-0.89)$ & 542 & $1.02(0.93-1.12)$ & 1026 & $0.87(0.81-0.93)$ \\
3 & 592 & $0.84(0.77-0.91)$ & 1426 & $0.91(0.86-0.96)$ & 529 & $1.05(0.96-1.12)$ & 1011 & $0.90(0.84-0.96)$ \\
4 & 580 & $0.93(0.85-1.02)$ & 1237 & $0.90(0.84-0.95)$ & 499 & $1.06(0.96-1.16)$ & 1024 & $0.97(0.91-1.04)$ \\
5 & 412 & $0.91(0.82-1.01)$ & 907 & $0.90(0.84-0.97)$ & 368 & $1.05(0.94-1.17)$ & 725 & $0.93(0.86-1.00)$ \\
p for trend & & 0.003 & & $<0.001$ & & 0.143 & & 0.009 \\
\hline
\end{tabular}

$\mathrm{n}$ - number of infant deaths; RR - rate ratio; CI - confidence interval. Other abbreviations as in Table 3. 
Table 5. Infant mortality from CNS and CVS malformations in microregions in the South and Southeast Region of Brazil in 1986-1990 and 1997-2001, according to quintiles of per capita pesticide consumption, stratified by the type of microregion

\begin{tabular}{|c|c|c|c|c|}
\hline \multirow[t]{2}{*}{ Period } & \multicolumn{2}{|c|}{$\begin{array}{c}\text { CNS } \\
(\mathrm{RR}(95 \% \mathrm{CI}))\end{array}$} & \multicolumn{2}{|c|}{$\begin{array}{c}\text { CVS } \\
(\text { RR }(95 \% \mathrm{CI}))\end{array}$} \\
\hline & urban & rural & urban & rural \\
\hline \multicolumn{5}{|c|}{ 1986-1990: pesticide use quintiles 1985} \\
\hline 1 & 1 & 1 & 1 & 1 \\
\hline 2 & $0.92(0.83-1.02)$ & $0.90(0.77-1.06)$ & $0.86(0.80-0.92)$ & $1.05(0.95-1.16)$ \\
\hline 3 & $0.92(0.83-1.02)$ & $1.02(0.88-1.18)$ & $0.88(0.82-0.95)$ & $1.07(0.97-1.18)$ \\
\hline 4 & $0.80(0.69-0.93)$ & $1.29(1.12-1.47)$ & $0.78(0.71-0.87)$ & $1.19(1.08-1.30)$ \\
\hline 5 & $0.87(0.74-1.02)$ & $1.18(1.01-1.37)$ & $1.00(0.90-1.11)$ & $1.10(0.99-1.21)$ \\
\hline $\mathrm{p}$ for trend & $<0.001$ & $<0.001$ & 0.106 & 0.004 \\
\hline \multicolumn{5}{|c|}{ 1997-2001: pesticide use quintiles 1996} \\
\hline 1 & 1 & 1 & 1 & 1 \\
\hline 2 & $1.01(0.92-1.10)$ & $0.97(0.82-1.14)$ & $0.96(0.91-1.02)$ & $0.89(0.78-1.00)$ \\
\hline 3 & $1.16(1.01-1.33)$ & $1.12(0.97-1.29)$ & $0.98(0.88-1.08)$ & $1.22(1.10-1.35)$ \\
\hline 4 & $1.11(0.95-1.28)$ & $1.14(0.98-1.34)$ & $0.91(0.82-1.01)$ & $1.16(1.03-1.30)$ \\
\hline 5 & $1.03(0.88-1.21)$ & $1.12(0.96-1.31)$ & $0.99(0.89-1.10)$ & $1.15(1.03-1.29)$ \\
\hline $\mathrm{p}$ for trend & 0.123 & 0.037 & 0.218 & $<0.001$ \\
\hline
\end{tabular}

Abbreviations as in Table 3.

and CVS defects $(\mathrm{RR}=1.39,95 \% \mathrm{CI}: 1.21-1.60$, in the 4th quintile). Regarding the 2 nd period, the increasing trend of mortality across pesticide use quintiles in rural microregions was statistically significant for CNS malformations among boys and for mortality due to CVS defects in both sexes. In this period, mortality RRs were particularly high among boys born in microregions in the 2nd quintile of pesticide consumption, i.e. $\mathrm{RR}=1.28$ (95\% CI: 1.04-1.59) and RR = 1.30 (95\% CI: 1.13-1.50) for CNS and CVS malformations, respectively.

\section{DISCUSSION}

The worldwide decrease of deaths from infectious-related diseases has led to a proportional increase in infant mortality from congenital defects in the last decades. In Brazil, such an increase in mortality from birth defects has occurred in parallel with a pronounced rise in pesticide consumption. Between 1988 and 1999, pesticide use in the country increased by $53 \%$, and in 2008, Brazil overtook USA as the largest consumer of pesticides [30]. To test the hypothesis of a relationship between pesticide use and occurrence of CNS and CVS congenital malformations in Brazil, we conducted an ecological study in the South Region and in the Southeast Region of the country, which constitute the most developed area of Brazil and thus underreporting of birth defects in this area is expected to be lower than in the North, Northeast and Central-West Regions.

The findings showed that per capita consumption of pesticides in rural microregions in 1985 and 1996 was positively correlated with infant mortality rates related with CNS malformations in 1986-1990 and CVS anomalies in 1997-2001, respectively, whereas in urban microregions these correlations were only observed among girls. Likewise, the risk of mortality due to the 2 types of congenital defects showed a significant trend of increase with increasing per capita consumption of pesticides in rural microregions, in the 2 study periods. Such an increase in mortality rates was not 


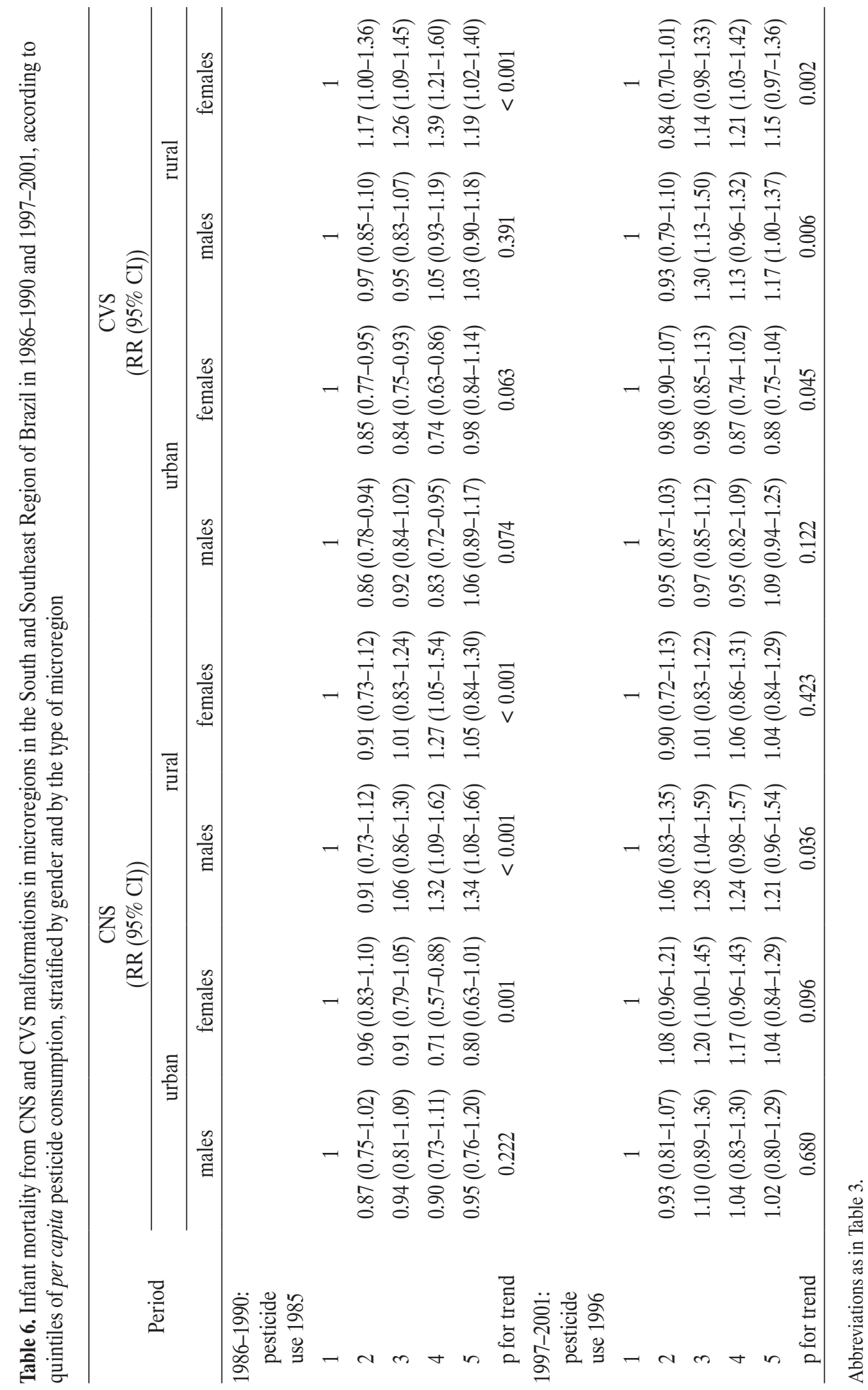


observed in urban microregions, suggesting that pesticide exposure may play an important role in the geographical distribution of mortality from congenital malformations only in rural areas. In urban environments, other risk factors of birth defects may prevail, including exposure to other environmental chemicals such as pesticides different than those used in field crops or rural activities.

The relationship observed in the rural microregions is of particular concern taking into account that, although agricultural workers in the South and Southeast Region of Brazil might have a higher risk perception from pesticide exposure [31,32] compared to other regions, it has been shown that knowledge and awareness of pesticide risks do not always lead to safety practices among Brazilian farmers [33,34]. Moreover, lower pesticide risk perception has been shown among women in agricultural population in Brazil [20,34], which may lead to a higher pesticide exposure even during pregnancy.

The main crops that are grown in the region under study are: sugar cane, coffee, soybean, corn, cotton, rice, wheat, orange, black beans and potato. Between the decades of 1980s and 1990s, the production of soybean increased greatly in the South and Southeast Region of the country, rising the amount of insecticides used in field crops. Through the decade of 1990s, the use of organophosphate pesticides, such as herbicide glyphosate (largely used in soybean crops) and insecticides methamidophos, acephate and carbendazim, underwent an appreciable increase in the study area. Pyrethroids insecticides such as cypermethrin were also introduced in Brazil during the 1990s. Exposure to different types of pesticides through the years under the study may explain some of the differences observed between the study periods, e.g. the association with pesticide use in the first period seemed to be stronger for CNS malformations, while the associations were stronger for CVS defects in the 2nd one. More detailed information about the specific types of pesticides used in individual microregions would provide a further insight into this relationship.
According to our knowledge, previous ecological studies found associations between pesticide use and CVS and/or CNS congenital malformations. In the USA, the occurrence of circulatory/respiratory malformations in high-wheat counties, an indicator of chlorophenoxy herbicide exposure, was significantly higher compared to lowwheat counties [35]. In addition, there was a stronger effect noted for infants conceived in spring, when pesticides were typically applied. A study also conducted in the USA reported higher rates of several birth defects, including spina bifida and CVS malformations, in infants conceived in the months with highest surface water concentrations of pesticides such as atrazine [4].

Regarding individual-level epidemiological studies, a casecontrol study in California found that women occupationally exposed to pesticides during pregnancy presented an increased risk of having a baby with a neural tube defect, among other anomalies [36]. The same research team reported that maternal residential proximity to areas of application of several specific pesticides during early gestation increased the risk of neural tube defects [23]. Anencephaly or spina bifida subtypes were also associated with exposure to different pesticides [23]. Women's pesticide exposures through household gardening, professional application or living in close proximity to agricultural crops were associated with increased risks of their offspring having neural tube defects and limb anomalies [36]. In Texas, Mexican women who reported using pesticides in their homes were 2 times more likely to have a live birth with spina bifida or anencephaly than non-exposed women [17]. Women with a neural tube defect-affected baby were also more likely to report living in the proximity to cultivated fields than control women [17]. Another study among Mexican women reported that working in agriculture around the time of conception was associated with a greater risk of anencephaly in the offspring [22]. More recently, a positive association has been found between placental concentrations of different organochlorine 
pesticides and increased risk of spina bifida or anencephaly [37].

Although CVS malformations are among the most common severe birth defects, epidemiological evidence of a link with pesticide exposure is limited. Thus, associations were noted between exposure to herbicide atrazine and excess of CVS defects [25], and between pesticide use and patent ductus/coarctation of the aorta [26]. Maternal exposure to domestic pesticides during the 1st trimester of pregnancy was associated with transposition of the great arteries in the offspring, particularly for exposure to herbicides and rodenticides [24].

Several other epidemiological studies also reported associations between pesticide exposure and a variety of congenital anomalies, particularly in the offspring of agricultural workers, in infants born to women living in the proximity of pesticide application areas or in babies conceived in a particular season [3,16-18,20,22,23,36]. In Brazil, one study found a greater risk of congenital defects in births to parents exposed to pesticides at work or due to proximity to an application area [20].

The concerns about fetal exposures to environmental hazards come from increasing understanding that the fetus is extremely sensitive during certain critical windows of development, and windows of sensitivity exist for many systems, such as the respiratory, immune, reproductive, nervous, cardiovascular, and endocrine systems [14]. Several animal studies have shown that numerous pesticide compounds may exert teratogenic effects, leading to reproductive outcomes such as congenital defects. In relation with the malformations under the study, some types of fungicides and insecticides have been shown to inhibit neuroepithelial cell development and neural tissue differentiation during neurulation [38-40], while some types of herbicides may induce teratogenic effects including ventricular septal defects among laboratory animals $[41,42]$. However, epidemiological evidence reported to date corroborating the link between prenatal pesticide exposure and risk of CNS, CVS and other birth defects is limited $[11,13]$. Overall, further individual-level epidemiological studies are needed examining this relationship. Future studies should address specific questions related with: particular windows of susceptibility for the developing fetus; specific pesticides that increase the risk; dose-response relationships, as suggested by Rull et al. (2006) [23]; gender differences; and genetic susceptibility.

Besides pesticide exposure, there are several known risk factors for CNS and CVS malformations. In the present study, data were obtained from the national mortality information system, which does not register individual data on the socioeconomic, health or lifestyle factors such as education, cigarette smoking, alcohol and drug consumption, health history, pregnancy illnesses, and vitamins intake. The lack of information on these potential risk factors represents a limitation of this study since it could have produced biased risk estimates.

The mortality data in our study are another potential source of bias. Birth defects are typically underreported when using birth certificates, in part because not all defects are apparent at birth, and because birth defects are not always actively assessed in the 1st year of life, which is the best method for fully ascertaining congenital malformations [43]. In Brazil, many deaths from congenital defects in the 1st year of life are considered as labor complications, not being registered as congenital malformations. A study examining the quality of notification of congenital malformations in the city of Campinas (São Paulo state, Southeast Brazil), based on the SINASC (Live Births National Information System), observed underreporting of $46.8 \%$ for all congenital defects and $36.4 \%$ for major birth defects [8]. Studies in the city of Rio de Janeiro (Southeast Brazil) also showed underreporting of birth defects from birth certificates based on the SINASC [7,44]. Considering that underreporting in rural areas may be higher than in urban areas, mortality ratios in this study might have been underestimated rather than overestimated. 
On the other hand, using mortality data to investigate the association with pesticide exposure could have also led to underestimated risks in the present study, since many congenital malformations do not lead to death, such as certain cases of spina bifida or transposition of the great arteries, which can undergo surgical treatments at specialized centers. Nevertheless, a high proportion of cases of CNS defects and most cases of CVS malformations are severe and incompatible with life. Taking into account that a high proportion of the Brazilian population does not live in economic conditions sufficient to access specialized health centers, mortality data may provide a good measure of the occurrence of these types of malformations, particularly for CVS defects, which are a major cause of postnatal deaths from congenital anomalies. In addition, it is noteworthy to mention that access to health care in Brazil is quite unequal, being lower in rural populations. Consequently, mortality due to congenital malformations in rural areas is very likely to be higher than in urban areas. This fact could have contributed to increase the estimated rate ratios observed in rural microregions compared to the urban ones.

An additional potential source of bias in this study is exposure misclassification since women getting pregnant through the 1st study period (e.g. 1986-1990) may have experienced different exposure levels. Nevertheless, assuming that pesticide use increased steadily through the study periods, exposure levels might have also increased from 1985 to 1990 and from 1996 to 2001. Thus, if exposure levels were higher than those used in this study, i.e. the sales in 1985 and 1996, mortality risk ratios (RR) might have been underestimated rather than overestimated. Finally, data on pesticide "consumption" may also be biased for 2 reasons: first, sales establishments' employers could have misreported information on pesticide expenditure; second, because there is a strong illegal market of pesticides in Brazil due to the lack of control by competent authorities [45].

\section{CONCLUSIONS}

Birth defects have an important public health impact in developing countries. In Brazil, the proportion of birth defects in infant mortality, previously obscured by infectious diseases, assumed great relevance with the epidemiologic transition. A causal link between pesticide exposure and CNS and CVS birth defects is plausible, but not proven by this ecological study. Nevertheless, findings from the present study suggest that pesticide exposure is related with the occurrence of CNS and CVS congenital malformations in rural areas in the South and Southeast Region of Brazil with intense agricultural activity. However, since underreporting of congenital malformations is common and might be particularly relevant in rural areas, these findings should be interpreted with caution.

\section{REFERENCES}

1. Horovitz DDG, Llerena Júnior JC, Mattos RA. Birth defects and health strategies in Brazil: An overview. Cad Saude Publica. 2005;21(4):1055-64.

2. Shi L, Chia SE. A review of studies on maternal occupational exposure and birth defects, and the limitations associated with these studies. Occup Med (Lond). 2001;51(4):230-44.

3. Thulstrup AM, Bonde JP. Maternal occupational exposure and risk of specific birth defects. Occup Med. 2006;56:532-43.

4. Winchester PD, Huskins J, Ying J. Agrichemicals in surface water and birth defects in the United States. Acta Paediatr. 2009;98(4):664-9, http://dx.doi.org/10.1111/j.16512227.2008.01207.x.

5. Monlleo IL, Gil-da-Silva-Lopes VL. Craniofacial anomalies: Description and evaluation of treatment under the Brazilian Unified Health System. Cad Saude Publica. 2006;22(5): 913-22.

6. Pereira PMH, Frias PG, Carvalho PI, Vidal SA, Figueiroa JN. [Hospital neonatal mortality in cohort of newborns in a maternity school in the Northeastern Region of Brazil, 2001-2003]. Epidemiol Servicos Saude. 2006;15(4):19-28. Portuguese. 
7. Guerra FAR, Llerena Jr. JC, Gama SGN, Cunha CB, Theme Filha MM. Birth defects in Rio de Janeiro, Brazil: An evaluation through birth certificates (2000-2004). Cad Saude Publica. 2008;24:140-9.

8. Luquetti DV, Koifman RJ. Quality of reporting on birth defects in birth certificates: Case study from a Brazilian reference hospital. Cad Saude Publica. 2009;25(8): 1721-31.

9. Hoffman J, Christianson R. Congenital heart disease in a cohort of 19.502 births with long-term follow-up. Am J Cardiol. 1978;42:641-7.

10. Roger VL, Go AS, Lloyd-Jones DM, Benjamin EJ, Berry JD, Borden WD, et al. Writing Group Members, American Heart Association. Heart disease and stroke statistics 2012 Update. Circulation. 2012;125:e2-e220.

11. Finnell RH, Gelineau-van Waes J, Bennett GD, Barber RC, Wlodarczyk B, Shaw GM, et al. Genetic basis of susceptibility to environmentally induced neural tube defects. Ann NY Acad Sci. 2000;919:261-77.

12. Jenkins KJ, Correa A, Feinstein JA, Botto L, Britt AE, Daniels SR, et al. American Heart Association Council on Cardiovascular Disease in the Young. Non-inherited risk factors and congenital cardiovascular defects: Current knowledge: A scientific statement from the American Heart Association Council on Cardiovascular Disease in the Young: Endorsed by the American Academy of Pediatrics. Circulation. 2007;115(23):2995-3014.

13. Sever LE. Looking for causes of neural tube defects: Where does the environment fit in? Environ Health Perspect. 1995;103(Suppl 6):165-71.

14. Selevan SG, Kimmel CA, Mendola P. Identifying critical windows of exposure for children's health. Environ Health Perspect. 2000;108(Suppl 3):451-5.

15. Woodruff TJ, Carlson A, Schwartz MJ, Giudice LC. Proceedings of the summit on environmental challenges to reproductive health and fertility: Executive summary. Fertil Steril. 2008;89:281-300, http://dx.doi.org/10.1016/j.fertnstert.2007.10.002.
16. Bell EM, Hertz-Picciotto I, Beaumout JJ. A case-control study of pesticides and fetal death due to congenital anomalies. Epidemiology. 2001;12:148-56.

17. Brender JD, Felkner M, Suarez L, Canfield MA, Henry JP. Maternal pesticide exposure and neural tube defects in Mexican Americans. Ann Epidemiol. 2010;20(1):16-22, http:// dx.doi.org/10.1016/j.annepidem.2009.09.011.

18. Garry VF, Schreinemachers D, Harkins ME, Griffith J. Pesticide appliers, biocides, and birth defects in rural Minnesota. Environ Health Perspect. 1996;104(4):394-9.

19. Shaw GM, Wasserman CR, O'Malley CD. Maternal pesticide exposures as risk factors for orofacial clefts and neural tube defects. Am J Epidemiol. 1995;141(Suppl 11):S3.

20. Silva TP, Moreira JC, Peres F. Are tick medications pesticides? Implications for health and risk perception for workers in the dairy cattle sector. Cien Saude Colet. 2012;17:311-25.

21. Garcia AM, Fletcher T, Benavides FG, Orts E. Parental agricultural work and selected congenital malformations. Am J Epidemiol. 1999;149:64-74.

22. Lacasaña M, Vázquez-Grameix $\mathrm{H}$, Borja-Aburto VH, Blanco-Muñoz J, Romieu I, Aguilar-Garduño C, et al. Maternal and paternal occupational exposure to agricultural work and the risk of anencephaly. Occup Environ Med. 2006;63(10):649-56, http://dx.doi.org/10.1136/ oem.2005.023333.

23. Rull RP, Ritz B, Shaw GM. Neural tube defects and maternal residential proximity to agricultural pesticide applications. Am J Epidemiol. 2006;163:743-53.

24. Loffredo CA, Silbergeld EK, Ferencz C, Zhang J. Association of transposition of the great arteries in infants with maternal exposures to herbicides and rodenticides. Am J Epidemiol. 2001;153(6):529-36.

25. Munger R, Kramer M, Hanson J, Burns T, Cherryholmes K, Hansler W Jr. Birth defects and pesticide-contaminated water supplies in Iowa. Presented at the Society for Epidemiologic Research meeting, Minneapolis, Minnesota, 9-12 June 1992. Ann NY Acad Sci. 1992;919:261-77. 
26. Merchant DL, Stallones L, Keefer S, Rickard R. An ecologic analysis of congenital anomalies and agricultural chemicals in Colorado, 1989-1991. J Agr Saf Health. 1996;2(4):197-206.

27. Brazilian Health Ministry. Office for Health Access. Department of Strategic Action Planning. Occupational Health Technical Area. [Guidelines for the integral assistance to occupational health of differential complexity. Pesticideexposed workers health assistance protocol]. Brasilia (DF): Health Ministry; 2006. Portuguese.

28. De Siqueira MT, Braga C, Cabral-Filho JE, Augusto LG, Figueiroa JN, Souza AI. Correlation between pesticide use in agriculture and adverse birth outcomes in Brazil: An ecological study. Bull Environ Contam Toxicol. 2010;84(6): 647-51, http://dx.doi.org/10.1007/s00128-010-0027-8.

29. Health Information Department of the Unified National Health System (DATASUS), Brazilian Ministry of Health [cited 2014 March 31]. Available from: www.datasus.saude. gov.br. Portuguese.

30. Sindicato Nacional da Industria de Produtos para Defesa Agricola. [Agropecuary production house] [cited 2013 March 20]. Available from: http://www.sindag.com.br/dados_mercado.php. Portuguese.

31. Peres F, Rozemberg B, de Lucca SR. Risk perception related to work in a rural community of Rio de Janeiro State, Brazil: pesticides, health, and environment. Cad Saude Publica. 2005;21:1836-44.

32. Peres F, Moreira JC, Rodrigues KM, Claudio L. Risk perception and communication regarding pesticide use in rural work: A case study in Rio de Janeiro State, Brazil. Int J Occup Environ Health. 2006;12:400-7.

33. Ribeiro MG, Colasso CG, Monteiro PP, Pedreira Filho WR, Yonamine M. Occupational safety and health practices among flower greenhouses workers from Alto Tietê region (Brazil). Sci Total Environ. 2012;416:121-6, http:// dx.doi.org/10.1016/j.scitotenv.2011.11.002.

34. Peres F, Rodrigues KM, da Silva Peixoto Belo MS, Moreira JC, Claudio L. Design of risk communication strategies based on risk perception among farmers exposed to pesticides in Rio de Janeiro State, Brazil. Am J Ind Med. 2013;56:77-89.

35. Schreinemachers DM. Birth malformations and other adverse perinatal outcomes in four U.S. Wheat-producing states. Environ Health Perspect. 2003;111:1259-64.

36. Shaw GM, Wasserman CR, O'Malley CD, Nelson V, Jackson RJ. Maternal pesticide exposure from multiple sources and selected congenital anomalies. Epidemiology. 1999;10:60-6.

37. Ren A, Qiu X, Jin L, Ma J, Li Z, Zhang L, et al. Association of selected persistent organic pollutants in the placenta with the risk of neural tube defects. Proc Natl Acad Sci USA. 2011;108(31):12770-5, http://dx.doi.org/10.1073/ pnas.1105209108.

38. Farag AT, El Okazy AM, El-Aswed AF. Developmental toxicity study of chlorpyrifos in rats. Reprod Toxicol. 2003;17:203-8.

39. Slotkin TA. Cholinergic systems in brain development and disruption by neurotoxicants: nicotine, environmental tobacco smoke, organophosphates. Toxicol Appl Pharmacol. 2004;198:132-51.

40. Yoon CS, Jin JH, Park JH, et al. The fungicide benomyl inhibits differentiation of neural tissue in the Xenopus embryo and animal cap explants. Environ Toxicol. 2003;18:327-37.

41. Buslovich S, Aleksashina ZA, Kolosovskaia VM. [Effect of phenobarbital on the embryotoxic action of 2-methyl-4-chlorophenoxyacetic acid]. Farmakol Toksikol. 1979;42:167-70. Russian.

42. Yasuda M, Maeda H. Teratogenic effects of 4-chloro2-methylphenoxyacetic acid ethylester (MCPEE) in rats. Toxicol Appl Pharmacol. 1972;23:326-33.

43. Martin JA, Hamilton BE, Sutton PD, Ventura SJ, Menacker F, Munson ML. Births: final data for 2003. Natl Vital Stat Rep. 2005;54:1-116.

44. Costa CMS, Gama SGN, Leal MC. [Congenital malformations in Rio de Janeiro, Brazil: prevalence and associated factors]. Cad Saude Publica. 2006;22:2423-31. Portuguese.

45. Soares W, Almeida RM, Moro S. [Rural work and risk factors associated with pesticide use in Minas Gerais, Brazil]. Cad Saude Publica. 2003;19(4):1117-27. Portuguese.

This work is available in Open Access model and licensed under a Creative Commons Attribution-NonCommercial 3.0 Poland License - http://creativecommons.org/ licenses/by-nc/3.0/pl/deed.en. 